\title{
Polarographic Determination of Lead and Cadmium in Zinc-Base Alloys, Using Electrolytic Separations at Controlled Potential
}

\author{
John K. Taylor and Stanley W. Smith
}

\begin{abstract}
A method is described for the polarographic determination of lead and cadmium in zinc-base alloys. It involves the separation of the metals from the zinc by electrolysis at controlled potential, using a mercury cathode. Fresh electrolyte is substituted for the residual solution and the metals are anodically redissolved from the mercury by controlledpotential electrolysis and determined by polarographic measurement. For lead and cadmium contents of a few ten-thousandths of a percent and greater, the determinations can be made with the usual precision of polarographic measurements.
\end{abstract}

\section{Introduction}

The determination of lead and cadmium in spelter and zinc-base alloys, in many cases, is most conveniently and accurately performed by polarographic methods. Several procedures of this type have been described $[1,2]^{1}$ and a method has been recommended by the American Society for Testing Materials [3].

All of the published methods are inapplicable when the copper content of the sample greatly exceeds that of lead and cadmium, because the copper wave precedes the waves of these metals and interferes with their determination. Methods have been described previously in which copper is made nonreducible by formation of the cyanide complex [4] or precipitated as copper acetylide [5], but these have not proved to be entirely satisfactory in the application described in this paper.

Even for alloys of low-copper content, the existing methods have a serious disadvantage when very small amounts of the metals are to be determined. In this case, it is necessary to increase the size of the sample and decrease the final volume of the test solution to obtain greater concentration of the metals and hence increased sensitivity. It is obvious that the concentration of zinc salts in the test solution will vary directly with the size of sample and inversely with the final volume of the solution. For example, the concentration of zinc salts will be 1.2 molar if a 2 -g sample is contained in $25 \mathrm{ml}$, but 3 molar if the final volume is $10 \mathrm{ml}$. Such large variations in the composition of the supporting electrolyte have a considerable effect on the diffusion-current constants of lead and cadmium [6] causing the calibration factor to vary with the size of sample.

The difficulties described above can be avoided and increased sensitivity can be obtained by separating the metals to be determined from the zinc by electrolysis at controlled potential, using a mercury cathode. When electrolysis is complete, the electrolyte may be discarded and the metals may be anodically dissolved in a suitable volume of the sup-

Figures in brackets indicate the literature references at the end of this paper. porting electrolyte. By proper selection of the potential, any interfering copper can be retained in the mercury anode and subsequently dissolved in a suitable electrolyte for polarographic determination.

\section{Experimental Details}

Polarographic measurements were made by using a Sargent model XII photographic-recording polarograph and a Sargent model XXI pen-recording instrument. Electrolyses at controlled potential were performed using the potentiostat described by Greenough, Williams, and Taylor [7]. The electrolysis cell used is shown in figure 1 . The cathode consisted of a pool of mercury, and the anode was a cylinder of platinum gauze. A small motor-driven stirrer was located at the mercury-solution interface to minimize concentration-polarization effects. The

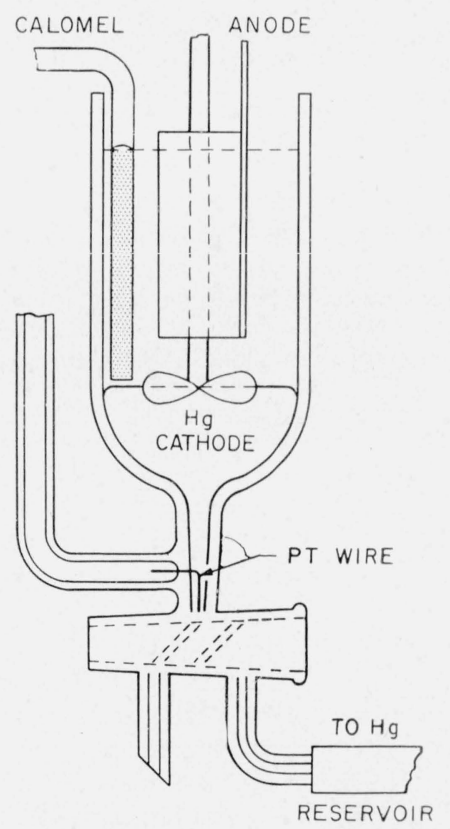

Figure 1. Cell used for electrolysis with mercury cathode at controlled potential. 
saturated-calomel reference electrode used was provided with an agar plug saturated with potassium chloride at the junction tip. This tip was placed close to the mercury-pool electrode to minimize $i R$ corrections.

The cell was provided with a platinum contact located as close as possible to the drain stopcock. It was thus possible to maintain electrical connection until virtually all of the mercury was drained. This is necessary to prevent partial resolution of electrolyzed material during the draining process. The capacity of the cell was $50 \mathrm{ml}$, with a minimum usable volume of about $20 \mathrm{ml}$. A polyethylene sheet provided with holes for introducing the stirrer and electrodes served as a cover to minimize loss of solution by spraying.

Solutions for calibrating the polarographic measurements were made by dissolving appropriate quantities of the pure metals. NBS Standard Samples and previously analyzed alloys were used to test the precision of the method.

All polarographic measurements were made by using comparative methods [6].

\section{Procedure}

The sample is dissolved in hydrochloric acid with the addition of a small amount of nitric acid or hydrogen peroxide, if necessary, to ensure complete solution. After boiling the solution to remove oxides of nitrogen (if present), it is cooled and transferred to the electrolysis cell. Approximately $0.1 \mathrm{~g}$ of hydrazine dihydrochloride is added to serve as an anodic depolarizer [8]. The calomel electrode is inserted as already described, the potentiostat is connected, and the electrolysis is performed at a cathode potential of $0.9 \mathrm{v}$ with respect to the saturated calomel electrode. This effectively separates the copper, lead, cadmium, and tin from zinc, which remains in the solution. Upon completion of the electrolysis, the current decreases to a small constant value approaching zero. While electrolysis is maintained, the mercury layer is drained from the cell and collected in a small clean beaker. The residual solution is removed and discarded, after which the mercury is returned to the cell and fresh electrolyte is introduced. This solution contains sufficient potassium chloride to make the final solution $0.1 \mathrm{~N}$ with respect to this salt. In addition, a few milligrams of hydrazine dihydrochloride are added to serve as a depolarizer to prevent the deposition of lead on the platinum electrode. The electrical connections are made as before but with the potential of the mercury electrode regulated to anodically dissolve the desired metals. At a potential of $0.35 \mathrm{v}$ with respect to the reference electrode, lead and cadmium will be stripped quantitatively from the amalgam, and copper will be retained in the mercury.

After electrolysis is complete, the solution is removed as described above and is prepared for polarographic examination. The solution is transferred to a volumetric flask, sufficient gelatin (maximum suppressor) is added to make the final solution 0.01 percent in this constituent, and the solution is diluted to volume. The polarograms are recorded and evaluated in the usual manner.

If it is desirable to determine copper, the residual mercury from above may be returned to the cell and electrolyzed in a similar manner to redissolve this metal. The supporting electrolyte and procedure recommended by Lingane [9] are useful in the determination of copper.

Tin is not reducible in the supporting electrolyte described above and hence does not interfere with the determination of lead. If the tin content of the alloy is of interest, the solution from the final electrolysis may be treated according to the method of Lingane [10]. For small amounts of tin, however, it is necessary to increase the size of the sample rather than to concentrate the solution from the final electrolysis, as tin is lost by volatilization during this process.

\section{Discussion}

The accuracy and precision of the method are illustrated by the results shown in table 1 . The

TABLE 1. Determination of lead and cadmium in zinc-base alloys

\begin{tabular}{|c|c|c|c|c|}
\hline & \multicolumn{2}{|c|}{$\mathrm{Pb}$ in- } & \multicolumn{2}{|c|}{$\mathrm{Cd}$ in- } \\
\hline & Sample 108 & Sample $94 \mathrm{~b}$ & Sample 108 & Sample $94 b$ \\
\hline Fresent $\left\{\begin{array}{l}1 \\
2 \\
3\end{array}\right.$ & $\begin{array}{c}\% \\
0.047 \\
.0470 \\
.0484 \\
.0461\end{array}$ & $\begin{array}{c}\% \\
0.006 \\
.0056 \\
.0050 \\
.0056\end{array}$ & $\begin{array}{c}\% \\
0.092 \\
.0918 \\
.0925 \\
.0898\end{array}$ & $\begin{array}{c}\% \\
0.002 \\
.0025 \\
.0022 \\
.0026\end{array}$ \\
\hline $\begin{array}{l}\text { A verage } \\
\text { A verage devia- } \\
\text { tion }\end{array}$ & $\begin{array}{r}.0472 \\
\pm .0008\end{array}$ & $\begin{array}{r}.0054 \\
\pm .0003\end{array}$ & $\begin{array}{r}.0914 \\
\pm .0010\end{array}$ & $\begin{array}{r}.0024 \\
\pm .0002\end{array}$ \\
\hline
\end{tabular}

samples analyzed, 108 and 94b, are NBS Standard Samples and contain the percentages of lead and cadmium shown. The amounts of copper in 94b and 108 were 1.01 and 0.0004 percent, respectively. Additions of large amounts of copper to solutions of sample 108 prior to electrolysis were without effect on the determined values of lead and cadmium.

The method has been used for the determination of lead and cadmium in six zinc-base die-casting alloys to be used as standard samples for spectrographic analysis. The lead and cadmium contents ranged from 0.0006 to 0.010 percent, with copper contents up to 1.5 percent. The results obtained polarographically are in excellent agreement with those obtained by cooperating laboratories using more laborious methods. However, as the reports from all of the cooperating analysts have not been received, a detailed comparison cannot be made at this time.

The accuracy and precision that may be expected depend to a large extent on the design of the cell and on the ability of the operator to make the cathode-electrolyte separations quickly and exactly. It is important in the construction of the cell that the platinum contact wire should come as close as 
possible to the stopcock, in order that the electric circuit be complete until nearly all of the cathode is drained. This prevents all but a very small part of the deposited metal from returning to the solution.

The method described, in comparison to many involving preliminary separations, is relatively rapid and requires little attention of the operator. After dissolution of the sample and preparation of the solution, requiring no more than a few minutes, the electrolyses require about $1 \mathrm{hr}$ for completion. The polarographic determination accounts for about $1 / 4$ $\mathrm{hr}$, so that about $1 \frac{1 / 2}{\mathrm{hr}}$ are required for the determination of the two metals in a single sample. As no attention is required during the electrolysis, a number of determinations can be made concurrently, provided more than one potentiostat is available.

The size of sample required varies with its composition, the capacity of the cell, and the final volume of the solution. In this work, it was convenient to use a final volume of $25 \mathrm{ml}$. A $1-\mathrm{g}$ sample was adequate for Sample 94b. In the case of several of the zinc-base die-casting alloys, it was necessary to concentrate the solution after the electrolysis by evaporation on a steam bath and to adjust the final volume to $10 \mathrm{ml}$, in order to obtain adequate sensitivity with a $1-\mathrm{g}$ sample.

It is advisable to limit the depolarizer left in the final solution to the smallest amount that will prevent the deposition of lead dioxide on the anode. It has been found that when hydrazine dihydrochloride is present to about 0.2 percent, the lead wave is distorted because of the presence of a maximum, and the cadmium diffusion-current plateau is not flat, making precise measurements difficult in the range of 1 to $10 \mu \mathrm{g} / \mathrm{ml}$ of lead and cadmium in the final solution.

The method of electrolysis at controlled potential recently has received considerable attention by analysts and is now established as an extremely useful technique. The resolution of metal from the cathode as described in this paper does not appear to have been used previously. ${ }^{2}$ It would appear

2 Since completion of this experimental work and manuscript, a general paper
describing electroly tic stripping has appeared, W. E. Schmidt and C. E. Bricker, describing electroly tic stripping has ap
J. Electrochem. Soc. 102, 623 (1955). to have considerable applicability, especially for those cases in which the residual solution from an electrolysis contains elements that would interfere in subsequent analytical operations. It is limited to operations with the mercury cathode because electrolytic resolution from a platinum electrode would no doubt result in mechanical losses of deposited metal.

\section{Summary}

A method for the determination of small amounts of lead and cadmium in zinc-base alloys is described. A solution of the sample is electrolyzed at controlled potential, using a mercury pool cathode. The residual solution is replaced by fresh electrolyte and the electrode potential is adjusted so that the separated metals are anodically dissolved from the mercury electrode, and determined by polarographic measurement. This method permits the determination of lead and cadmium in these alloys, down to a few ten-thousandths of a percent, with the usual polarographic precision.

\section{References}

[1] R. C. Hawkins and H. G. Thode, Ind. Eng. Chem., Anal. Ed. 16, 71 (1944).

[2] W. Kilian, Analyse der Metalle, Bd. I, p. 442, Schiedsverfahren, Springer, Berlin (1942).

[3] ASTM Methods of Chemical Analysis of Metals, p. 428 (American Society for Testing Materials, Philadelphia, Pa., 1950).

[4] M. Spalenka, Z. anal. Chem. 126, 49 (1943).

[5] M. Sherman, Foundry $\mathbf{7 8 , 9 4}(1950)$

[6] J. K. Taylor, Anal. Chem. 19, 370 (1947).

[7] M. L. Greenough, W. E. Williams, Jr., and J. K. Taylor. Rev. Sci. Instr., 22, 484 (1951).

[8] J. J. Lingane and S. Jones, Anal. Chem. 23, 1804 (1951).

[9] J. J. Lingane, Ind. Eng. Chem., Anal. Ed. 16, 147 (1944).

[10] J. J. Lingane, Ind. Eng. Chem., Anal. Ed. 18, 429 (1946).

Washington, February 13, 1956. 